\title{
Understanding the Personality Traits of Medical Students Using the Five Factor Model
}

\author{
Mustaffa, M. B. ${ }^{1}$, Nasir, R. ${ }^{2}$, Khairudin, R. ${ }^{2}$, Zainah, A. Z. ${ }^{2}$, Wan Shahrazad, W. S. ${ }^{2}$ \& Syed Salim, S. S. ${ }^{1}$ \\ ${ }^{1}$ Department of Psychology and Counselling, Universiti Pendidikan Sultan Idris, Tanjong Malim, Malaysia \\ 2 School of Psychology \& Human Development, Faculty of Social Sciences \& Humanities, Universiti \\ Kebangsaan Malaysia, Bangi, Malaysia \\ Correspondence: Nasir, R., School of Psychology and Human Development, Faculty of Social Sciences and \\ Humanities, Universiti Kebangsaan Malaysia, 43600 UKM Bangi, Selangor, Malaysia. Tel: 60-3-8921-5202. \\ E-mail: rohany@ukm.my
}

Received: June 4, 2012 Accepted: June 16, $2012 \quad$ Published: July 16, 2012

doi:10.5539/ass.v8n9p17 URL: http://dx.doi.org/10.5539/ass.v8n9p17

\begin{abstract}
Performance of both medical students and doctors is influenced by certain personality characteristics. It is therefore important to choose students with the right personality besides excellent performance academically for medical schools. The main objective of this study was therefore to ascertain the personality of students studying medicine based on gender and year of study. Participants for this study were 1029 medical students in seven universities in Peninsular Malaysia. They were selected by stratified random sampling. NEO personality Inventory-Revised was used to measure personality. Results showed that the medical students differ significantly in openness, agreeableness and conscientiousness based on gender. Female students scored higher on conscientiousness than male students. Apart from that the fifth year students scored highest on conscientiousness and lowest on neuroticism compared to those in the lower year of study. The implication of this study indicated that places in medical study program should be given to students with the right personality besides having excellent academic results.
\end{abstract}

Keywords: personality traits, neuroticism, extraversion, openness, agreeableness, conscientiousness, medical students

\section{Introduction}

Issues pertaining to performance among medical doctors such as professional misconduct should not be taken lightly because they affect the well being of their patients. Studies had shown that those issues are related to both unprofessional behavior and poor academic achievement while in medical schools (Doherty and Nugent, 2011). Performance of both medical students and doctors is influenced by certain personality characteristics and studies also showed significant associations between certain personality profiles and poor performance and stress (Doherty and Nugent, 2011; Leivens et al., 2002; Hoschl and Kozeny, 1997). Gough (2004) suggests that five personality traits and intellectual qualities that are required being professional physicians such as competence, character, common sense, creativity and courage. As such personality besides academic performance is an important factor in the selection of students into medical training.

The ability to solve problem, critical thinking, communication skill, integrity, empathy and language skill are also important (Marley and Carman, 1999). Research by Chibnall et al. (2009) showed that extraversion and openness influence self development, leadership and problem solving among medical students. Results of a study by Mirsaleh et al. (2010) showed that there was positive correlation between openness and conscientiousness and negative correlation between neuroticism and satisfaction with clinical training.

A positive relationship between personality characteristics and mental health, coping and academic success of medical students was also found (Borges and Savickas, 2002). In terms of adjustment to college life among 
medical students, Klasner and Pistole (2003) discovered the influence of personality and social support. It is also important for students to have a stable personality during medical studies (Hughes, 2002).

Generally, the five-factor personality model is applicable in the assessment of personality for jobs (Ferguson et al., 1994). High scores in conscientiousness and low scores in neuroticism are associated with success in training (Barrick and Mount, 1991; Salgado, 1997). In terms of success in medical school, Ferguson et al. (2000) and Lievens et al. (2002) found that conscientiousness is a significant predictor. Busato et al. (2000) pointed out that conscientiousness had been consistently associated with academic performance. Apart from conscientiousness, agreeableness also had been associated with students' grades (Chowdhry and Amin, 2006).

Conscientiousness and openness to experience are also related (Lievens et al., 2002). High scores in conscientiousness and low scores in neuroticism are related to success in training and high scores in extraversion are related to interpersonal skill (Salgado, 1997; Salgado and Rumbo, 1997). Neuroticism has been found to be related with university students. For example, Premuzic and Furnham (2003) have found a negative correlation between neuroticism and academic achievement

Openness to experience is also related to university student. Openness to experience has been found to be significantly correlated with academic achievement (Farsides and Woodfield, 2003; Philips et al., 2003). Further, poor personality traits and negative coping styles appear to play a role in the physical and psychological health of medical students (Wang and Miao, 2009).

It is therefore quite obvious that certain personality characteristics are important for performance, success, adjustment and physical as well as psychological health of medical students. As such choosing students with the right personality is important in ensuring their suitability for medical schools since they are future doctors. The objective of this study is to ascertain the personality traits of medical students studying in seven universities in Malaysia.

\section{Methods}

This is a cross sectional study using a set of questionnaire. Participants for this research were 1,029 medical students from seven universities in peninsular Malaysia who were selected by stratified random sampling procedure. They were 271 first year, 219 second year, 228 third year, 177 fourth year and 134 fifth year students.

NEO Personality Inventory-Revised (NEO-PI-R; Costa \& McCrae, 1992) containing 240 items was the instrument used to measure neuroticism, extraversion, openness, agreeableness and conscientiousness. Each factor contains a total of 48 items (both negative and positive items combined). Each item is rated on a five-point Likert scale from $1=$ disagree strongly to $5=$ agree strongly. The reliability of NEO-PI-R for the Malay version was: neuroticism $=0.885$; extraversion $=0.888$; openness $=0.797$; agreeableness $=0.864$; and conscientiousness $=0.911$. The inventory was back translated into the Malay language using Brislin et al.'s (2004) back translation technique.

The research instrument was distributed only after written consents were obtained from all seven universities. The data were analyzed using t-test and one-way ANOVA.

\section{Results and Discussion}

T-test was used to find out the difference in personality based on gender. The results showed a significant difference in openness between male and female students, $t(1027)=-2.03, p<0.05$. The mean value for female students 151.69 was significantly higher than the male students 150.29 . Female students also scored significantly higher on agreeableness with the mean value of 163.73 compared to 159.99 of that of the male students, $t(1027)$ $=-4.34, \mathrm{p}<0.001$. Female students also obtained significantly higher scores on conscientiousness with the mean of 163.80 compared to male students $160.76, \mathrm{t}(1027)=-2.80, \mathrm{p}<0.05$ which showed that female students were more diligent and had a better ability in controlling their impulse.

The results of the $t$ test showed no significant difference in neuroticism $(1027)=-1.70, p>0.05$, and extraversion $\mathrm{t}(1027)=-0.28, \mathrm{p}>0.05$ between the two groups of students. Table 1 below shows the results of the $\mathrm{t}$-test analysis for the five traits of personality. (refer to Table 1). 
Table 1. T-test analysis for neuroticism, extraversion, openness, agreeableness and conscientiousness based on gender

\begin{tabular}{llccccc}
\hline Domain & Gender & $\mathrm{N}$ & Mean & $\mathrm{SD}$ & $\mathrm{df}$ & $\mathrm{t}$ \\
\hline Neuroticism & Male & 403 & 145.71 & 17.28 & 1027 & -1.70 \\
& Female & 626 & 147.51 & 16.20 & & \\
Extraversion & Male & 403 & 154.49 & 14.54 & 1027 & -.28 \\
& Female & 626 & 154.76 & 15.18 & & \\
Openness & Male & 403 & 150.29 & 10.44 & 1027 & $-2.03^{*}$ \\
& Female & 626 & 151.69 & 11.03 & & \\
Agreeableness & Male & 403 & 159.99 & & 1027 & $-4.34^{* * *}$ \\
& Female & 626 & 163.73 & 14.16 & & \\
& Male & 403 & 160.76 & 17.42 & 1027 & $-2.80^{* *}$ \\
& Female & 626 & 163.80 & 16.69 & & \\
\hline
\end{tabular}

$* \mathrm{p}<0.5, \quad * * \mathrm{p}<0.01, * * * \mathrm{p}<0.001$

The difference in personality based on year of study was analyzed using one-way ANOVA. Results of one-way ANOVA analysis showed that there were significant differences in neuroticism $[\mathrm{F}(4,1024)=4.57, \mathrm{p}<0.001]$ and conscientiousness $[\mathrm{F}(4,1024)=2.68, \mathrm{p}<0.05]$ based on year of study. However, there was no significant difference in extraversion $[\mathrm{F}(4,1024)=1.20, \mathrm{p}>0.05]$, openness $[\mathrm{F}(4,1024)=1.23, \mathrm{p}>0.05]$ and agreeableness $[F(4,1024)=1.02, p>0.01]$ based on year of study. The results are shown in Table 2. (see Table 2). In addition, Tukey Post Hoc analysis was performed and the results are shown in Table 3. (see Table 3).

Table 2. Results of one-way ANOVA on differences of personality based on year of study

\begin{tabular}{llcccc}
\hline \multicolumn{1}{c}{ Personality } & \multicolumn{1}{c}{ Source } & SS & df & MS & F \\
\hline Neuroticism & Between Groups & 4993.75 & 4 & 1248.44 & $4.57^{* *}$ \\
& Within Groups & 279954.60 & 1024 & 273.393 & \\
Extraversion & Between Groups & 1066.00 & 4 & 266.50 & 1.20 \\
& Within Groups & 22799 & 1024 & 222.64 & \\
Openness & Between Groups & 574.81 & 4 & 143.70 & 1.23 \\
& Within Groups & 119713.59 & 1024 & 116.91 & \\
Agreeableness & Between Groups & 708.70 & 4 & 177.18 & 1.02 \\
& Within Groups & 178248.46 & 1024 & 174.07 & \\
Conscientiousness & Between Groups & 3093.18 & 4 & 773.296 & $2.68^{*}$ \\
& Within Groups & 295197.98 & 1024 & 288.279 & \\
\hline
\end{tabular}

$* \mathrm{p}<0.05, * * \mathrm{p}<0.01$

Table 3. Tukey Post Hoc analysis for neuroticism and conscientiousness based on year of study

\begin{tabular}{llll}
\hline Personality & Year of Study (Mean) & Year of Study (Mean) & Difference in Mean \\
\hline Neuroticism & Year One & Year Five & \\
& 147.78 & 141.96 & $5.82^{*}$ \\
& Year Two & Year Five & \\
& 149.27 & 141.96 & $7.31^{*}$ \\
& Year Three & Year Five & \\
& 146.94 & 141.96 & $4.98^{*}$ \\
Conscientiousness & Year Four & Year Two & \\
& 164.27 & 159.57 & $4.71^{*}$ \\
\hline
\end{tabular}

$* \mathrm{p}<\overline{0.05}$

Table 3 shows results of Tukey Post Hoc analysis which shows a significant difference in neuroticism of year two students with the mean of 149.27 compared to students in year five whose mean was 141.96. This means that the second year students had a higher inclination to experience feeling scared, angry, sad, shy, and guilty, hate towards others compared to students in the fifth year. The results also shows that the means for neuroticism of the first year students (147.78) and the third year students' (146.94) was also significantly higher than the fifth year students'.

As for conscientiousness, the results of the Tukey Post Hoc analysis shows that the fourth year students' mean of 164.27 was significantly higher than the second year students with the mean 159.57. This shows that the fourth 
year students have a better ability to control their impulses, efficient in planning and in managing their tasks compared to the second year students. No significant difference was found in the means for extraversion, openness and agreeableness among the medical students based on year of study.

Results of the study showed significant difference in openness, agreeableness and conscientiousness based on gender. Female students had higher mean score on openness which means they were more open than the male students which indicated that female students were more imaginative, sensitive towards the esthetics, pay more attention to feelings, like varieties, intellectual, and were not dependent on other people's assessment compared to the male students (Costa and McCrae, 1992). The social and cultural factors also had an influence on female students in their personality development. The society and culture expect women to be feminine; therefore it is no wonder that female medical students in this study had high scores on agreeableness and conscientiousness.

Agreeableness trait has an interpersonal dimension which means that the female students were more sympathetic towards others, like to help others and believed that one day others would also help them in return (Costa and McCrae, 1992). Female students compared to male students had a higher tendency to think of other people's needs and welfare more than their own, being good, careful, ever willing to help, flexible, compromising, not prejudice and sympathetic (Costa and McCrae, 1992).

Female students had higher scores on conscientiousness compared to male students which indicate that female students were more hardworking than the male students. They were also comparatively better at making plans, manage and carry out tasks. Individuals who are high on conscientiousness are determined, firm and courageous in decision making. High score in conscientiousness is also related to high academic and career achievement. A study by Lievens et al. (2002) revealed that conscientiousness is a reliable predictor of academic success.

Being students in medical training can be very stressful (Saipanish, 2003; Radcliffe and Lester, 2003). The characteristics in conscientiousness which emphasize on quality and achievement are necessary in the medical field because it is a very stressful and demanding field. Diligence, determination and efficient are important characteristics in order to perform well as medical students and as medical doctors. Also research had found that medical students with high conscientiousness would have a low depression (Nasir et al., 2011) which means that those with high scores on conscientiousness are healthier mentally.

It is very interesting to note that results of this study showed that there were significant differences in neuroticism and conscientiousness among the medical students based on their year of study. The fifth year students scored lowest on neuroticism compared to the first, second, third and fourth year students. Neuroticism is linked to less effective coping styles (Parker, 1986) and had direct positive effect on immature coping style (Wang and Miao, 2009). In this regard, low score in neuroticism implies that the fifth year students were more stable emotionally and they were also less impulsive compared to the other four groups of students apart from having mature coping style. This is a very good development since medical doctors need to not only deal with patients but also their families and the general public. It is very important for the doctors to always be very careful, patient, able to control their emotions especially when faced with critical and crisis situations. They also need to be calm and have strong coping abilities.

Students in the fifth year of study also scored higher on conscientiousness compared to those in the fourth, third, second and first years. This shows that the training that they have been through was successful in making them more discipline, besides being efficient in making plans, management and in doing their tasks. Medical training had also made them more prepared to deal with the challenges and the demands of being in the medical profession.

\section{Conclusion}

This study had shown very interesting results indicating that based on gender the medical students differ significantly in openness, agreeableness and conscientiousness. Female students scored higher on conscientiousness than male students. Apart from that the fifth year students scored highest on conscientiousness and lowest on neuroticism compared to those in the lower year of study. This also shows that medical training had enabled the students to be better prepared to be doctors. This study has an implication on the selection of medical students. It is pertinent that scholarships and places in medical schools be given to students who not only excel academically but also who have the right personality for medical schools and as future doctors.

\section{References}

Barrick, M. R., \& Mount, M. K. (1991). The Big Five personality dimensions and job performance: A meta-analysis. Personnel Psychology, 44(1), 1-26. http://dx.doi.org/10.1111/j.1744-6570.1991.tb00688.x 
Borges, N. J., \& Savickas, M. L. (2002). Personality and medical specialty choice: A literature review and $\begin{array}{lllll}\text { interrogation. Journal of } & \text { Career }\end{array}$ http://dx.doi.org/10.1177/10672702010003001

Brislin, R. W., Macnab, B., \& Bechtold, D. (2004). Translation. In C.D. Spielberger (Ed.), Encyclopedia of applied psychology (Vol. 3). San Diego: Elsevier.

Busato, V. V., Prins, F. J., Elshout, J. J., \& Hamaker, C. (2000). Intellectual ability, learning style, achievement motivation and academic success of psychology students in higher education. Personality and Individual Differences, 29(6), 1057-1068. http://dx.doi.org/10.1016/S0191-8869(99)00253-6

Chibnall, J. T., Blaskiewicz, R. J., \& Detrick, P. (2009). Are medical students agreeable? An exploration of personality in relation to clinical skills training. Medical Teacher, 31(7), 311-315. http://dx.doi.org/10.1080/01421590802638006

Chowdhury, M., S., \& Amin, M. N. (2006). Personality and students' academic achievement: Interactive effect of conscienciousness and agreeableness on students' performance in principles of economics. Social Behaviour and Personality, 34(4), 381-388.

Costa, P. T. Jr., \& McCrae, R. R. (1992). NEO PI-R. Professional Manual. N. Florida Ave: Psychological Assessment Reources, Inc.

Doherty, E. M., \& Nugent, E. (2011). Personality factors and medical training: A review of the literature. Medical Education Review, 45(2), 132-140. http://dx.doi.org/10.1111/j.1365-2923.2010.03760.x.

Farsides, T., \& Woodfield, R. (2003). Individual differences and undergraduate academic success: The roles of personality, intelligence and application. Personality and Individual Differences, 34(7), 1225-1243. http://dx.doi.org/10.1016/S0191-8869(02)00111-3

Ferguson, E., Sanders, A., O'Hehir, F., \& James, D. (2000). Predictive validity of personal statements and the role of the five-factor model of personality in relation to medical training. Journal of Occupational and Organizational Psychology, 73(1), 321-344. http://dx.doi.org/10.1348/096317900167056

Ferguson, F., Payne, T., \& Anderson, N. (1994). Occupational personality assessment. Theory, structure and psychometrics of the OPQ FMX-5 student. Personality and Individual Differences, 17(1), 217-225. http://dx.doi.org/10.1016/0191-8869(94)90028-0

Gough, H. G. (2004). How to select medical students: A second look. Medical Teacher, 26(5), 479-480.

Hoschl, C., \& Kozeny, J. (1997). Predicting academic performance of medical students: The first three years. American Journal of Psychiatry, 154(6), 87-92.

Hughes, P. (2002). Can we improve on how we select medical students? Royal Society of Medicine (Great Britain). Journal of the Royal Society of Medicine, 95(1), 19-22.

Klasner, L., \& Pistole, M. C. (2003). College adjustment in a multiethnic sample: Attachment, separation-individuation, and ethnic identity. Journal of College Student Development, 44(1), 92-109. http://dx.doi.org/10.1353/csd.2003.0006

Lievens, F., Coetsier, P., De- Fruyt, F., \& De Maeseneer, J. (2002). Medical students' personality characteristics and academic performance: A five-factor model perspective. Medical Education, 36(11), 1050-1056. http://dx.doi.org/10.1046/j.1365-2923.2002.01328.x

Marley, J., \& Carman, L. (1999). Selecting medical students: A case report of the need for change. Medical Education, 33(6), 455-459. http://dx.doi.org/10.1046/j.1365-2923.1999.00345.x

Mirsaleh, Y. R., Tabatabaee, A., Rezai, Kivi, S.R., \& Ghorbani, R. (2010). The role of religiosity, coping strategies, self-efficacy and personality dimensions in the prediction of Iranian undergraduate rehabilitation interns' satisfaction with their clinical experience. Clinical Rehabilitation, 24(12), 1136-1143. http://dx.doi.org/10.1177/0269215510375907

Nasir, R., Mustaffa, M. B., Wan Shahrazad, W.S., Khairudin, R., \& Syed Salim, S. S. (2011). Parental support, personality, self-efficacy as predictors for depression among medical students. Pertanika Journal of Social Sciences \& Humanities, 19(S), 9-15.

Parker, K. P. (1986). Coping with stressful episodes: The role of individual differences, environmental factors, and situational characteristics. Journal of Personality and Social Psychology, 51, 1277-1292. http://dx.doi.org/10.1037/0022-3514.51.6.1277

Phillips, P., Abraham, C., \& Bond, R. (2003). Personality, cognition, and university students' examination performance. European Journal of Personality, 17, 435-448. http://dx.doi.org/10.1002/per.488 
Premuzic, T. C., \& Furnham, A. (2003). Personality traits and academic examination performance. European Journal of Personality, 17(6), 237-250. http://dx.doi.org/10.1002/per.473

Radcliffe, C., \& Lester, H. (2003). Perceived stress during undergraduate medical training: A qualitative study. Medical Education, 37(1), 32-38. http://dx.doi.org/10.1046/j.1365-2923.2003.01405.x

Saipanish, R. (2003). Stress among medical students in a Thai medical school. Medical Teacher, 25(5), 502-506. http://dx.doi.org/10.1080/0142159031000136716

Salgado, J. F. (1997). The five factor model of personality and job performance in the European community. Journal of Applied Psychology, 82(1), 30-43. http://dx.doi.org/10.1037/0021-9010.82.1.30

Salgado, J. F., \& Rumbo, A. (1997). Personality and job performance in financial service managers. International Journal of Selection and Assessment, 5(2), 91-100. http://dx.doi.org/10.1111/1468-2389.00049

Wang, W., \& Miao, D. (2009). The relationship among coping styles, personality traits and mental health of Chinese medical students. Social Behaviour and Personality, 37(2), 163-172. http://dx.doi.org/10.2224/sbp.2009.37.2.163 